\title{
Aplicação do Alinhamento Cognitivo em disciplinas de Geociểncias de um Curso de Engenharia de Petróleo e Gás
} Application of Cognitive Alignment in Geoscience disciplines of an Oil and Gas Engineering Course

\author{
Joemes de lima Simas ${ }^{1}$, Giorgio Basilicl' ${ }^{2}$ Celso Dal Ré Carneiro² \\ 1 - Doutoranda, Programa de Pós-Graduação em Ensino e História de Clências da Terra, Instituto de Geociências, Universidade Estadual de Campinas, Campinas, \\ SP, BRASIL. \\ 2 - Docente do Programa de Pós-Graduação em Ensino e História de Clências da Terra, Instituto de Geociências, Universidade Estadual de Campinas, Bolsista do \\ CNPQ, CAMPInAS, SP, Brasil. \\ E-MAIL: JOEMES.SIMAS@GMAIL.COM, BASILIII@UNICAMP.BR, CEDREC@UNICAMP.BR.
}

\begin{abstract}
Technological advances, thanks to the expansion of the oil and gas industry in the State of Amazonas, encouraged the Federal University of Amazonas (UFAM) to create an undergraduate course in Oil and Gas Engineering in 2010. In this course, the disciplines of Geosciences are essential for the student to understand the origin of hydrocarbon deposits and, subsequently, to develop research, exploitation and processing activities. This article describes teaching strategies based on the concept of Cognitive Alignment, which aroused students' interest and encouraged participation in the disciplines of Petroleum Geophysics and Geological Modeling. Conceptual maps, free and/or commercial software, assembly of teaching equipment and the use of virtual teaching-learning environments were utilized in the classroom. The use of didactic strategies in the disciplines of Reservoir Geological Modeling and Petroleum Geophysics allowed important results to be achieved in the teaching-learning process. The teaching alternatives can be replicated in other technical and higher-level courses in Oil and Gas Engineering.
\end{abstract}

Resumo: 0 avanço tecnológico, graças à expansão da indústria de petróleo e gás no Estado do Amazonas, incentivou a Universidade Federal do Amazonas (UFAM) a criar, em 2010, um curso de graduação em Engenharia de Petróleo e Gás. Neste curso as disciplinas de Geociências são essenciais para 0 estudante entender a origem das jazidas de hidrocarbonetos e, posteriormente, desenvolver atividades de pesquisa, explotação e beneficiamento. Este artigo descreve estratégias de ensino baseadas no conceito de Alinhamento Cognitivo, que despertaram 0 interesse dos alunos e fomentaram participação nas disciplinas de Geofísica do Petróleo e Modelagem Geológica. Foram utilizados, em sala de aula, mapas conceituais, softwares livres e/ou comerciais, montagem de equipamentos didáticos e uso de ambientes virtuais de ensino-aprendizagem. A utilização das estratégias didáticas nas disciplinas de Modelagem Geológica de Reservatórios e Geofísica do Petróleo permitiu atingir resultados importantes no processo de ensino-aprendizagem. As alternativas de ensino podem ser replicadas em outros cursos técnicos e superiores de Engenharia de Petróleo e Gás.
Citation/Citação: Simas, J. L., Basilici, G., \& Carneiro, C. D. R. (2021). Aplicação do Alinhamento Cognitivo em disciplinas de Geociências de um Curso de Engenharia de Petróleo e Gás. Terræ Didatica, 17(Publ. Contínua), 1-11, e021015. doi: 10.20396/ td.v17i00.8663568.

Keywords: Didactics, Undergraduate courses, Geosciences, Engineering, Aprendizagem significativa.

Palavras-chave: Didática, Ensino Superior, Geociências, Engenharia, Aprendizagem significativa.

\section{Manuscript/Manuscrito:}

Received/Recebido: 12/12/2020

Revised/Corrigido: 22/02/2021

Accepted/Aceito: 16/03/2021

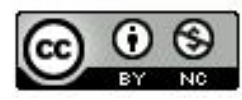

\section{Introdução}

Nos últimos anos, houve grande avanço tecnológico no Estado do Amazonas, sobretudo graças à expansão da indústria regional de petróleo e gás. Diante da contínua demanda por mão-de-obra qualificada, capaz de implementar novas tecnologias, a Universidade Federal do Amazonas (UFAM) decidiu criar, atendendo à Resolução n ${ }^{\circ} 045$, de 01 de outubro de 2009 do Egrégio Conselho Universitário (Consuni), o curso em Engenharia de Petróleo e Gás, integrado à Faculdade de Tecnologia FT/ UFAM. Oficialmente, o curso iniciou atividades no ano de 2010, com a primeira turma formada por cinquenta alunos matriculados.
$\mathrm{Na}$ grade curricular de 2010, as disciplinas de Geociências ofereceram bases para que os estudantes possam compreender a origem das jazidas de hidrocarbonetos. No entanto, o curso carece de laboratórios específicos para disciplinas de Geologia do Petróleo, Geofísica do Petróleo, Modelagem Geológica, Mecânica das Rochas e Introdução à Análise de Bacias, fazendo com que o ensino se torne demasiadamente teórico e a aprendizagem, lenta e cansativa. Em consequência, as disciplinas apresentaram a maior taxa de retenção de alunos. Um fator adicional refere-se à formação dos professores, composta por bacharéis que possuem formação técnica, mas são desprovidos de formação pedagógica.

\begin{tabular}{c|c|c|c|c|c}
\hline (C) Terrae Didat. & Campinas, SP & v.17 & $1-11$ & $\mathrm{e} 021015$ & 2021 \\
\hline
\end{tabular}


Uma barreira a ser considerada é a do envolvimento docente: é necessário visualizar as diferentes formas de utilizar os recursos tecnológicos nas aulas e "perceber os benefícios pedagógicos de integrar as tecnologias ao ensino" (Alvarenga, 2011, p.155). O replanejamento das disciplinas de Geociências teve como ponto de partida a demanda discente, tanto para conceber temáticas a serem tratadas em sala de aula, quanto para o desenvolvimento e aplicação dos conteúdos. A definição prévia dos objetivos de aprendizagem envolveu verbos bem específicos, para estabelecer com clareza os conceitos e habilidades que o aluno deveria dominar ao final das atividades.

O objetivo central da pesquisa descrita neste artigo é elaborar estratégias didáticas de ensino em Geociências para aprimorar o processo de ensino-aprendizagem no ensino de graduação e estimular os estudantes do curso de Engenharia de Petróleo e Gás nas disciplinas de Geociências, em particular em Geofísica do Petróleo e Modelagem Geológica de Reservatórios, este artigo sintetiza resultados do projeto de pesquisa desenvolvido pela primeira autora (JLS), sob orientação dos demais autores

\section{Fundamentação didática}

São muitos os desafios que se apresentam aos cursos superiores em Engenharia no Brasil, cuja demanda principal, dentre outros aspectos, é o uso intensivo da Ciência e das Tecnologias Digitais de Informação e Comunicação (TD) para formação profissional. As competências e habilidades desejáveis associam-se à capacidade de coordenar informações, manter interrelações saudáveis com pessoas, além de possuir sensibilidade humana para reconhecer e interpretar as possibilidades e/ou carências do contexto brasileiro e mundial (Rabelo et al., 2012).

Nesta pesquisa o Alinhamento Cognitivo ("Cognitive Alingment”) de John Biggs (1999), é proposto como forma de planejar o ensino de graduação além de conectar e sincronizar as ações de ensino e de avaliação. O Alinhamento Cognitivo, também conhecido como Alinhamento Construtivo, é um método de ensino que se concentra nos resultados de aprendizagem a serem alcançados pelos estudantes. Biggs (1999) propõe que tanto as atividades de ensino e aprendizagem quanto a avaliação devam estar alinhados aos resultados pretendidos da aprendizagem.

$\mathrm{Na}$ Taxonomia SOLO (Structure of the Observed
Learning Outcome / Estrutura de Resultado Observado de Aprendizagem, Biggs \& Tang, 2011), o Alinhamento Cognitivo requer o estabelecimento dos resultados pretendidos da aprendizagem, representados pelos objetivos de aprendizagem. Dependendo da habilidade ou capacidade desejada, os objetivos podem ser atingidos ou não, o que torna o processo de avaliação mais realista. Ao se estabelecer que o aluno deverá ser capaz de explicar determinado conceito ou realizar um procedimento, esse nível pertence a um estágio elementar ou básico. Um objetivo estabelecendo que o aluno deverá ser capaz de comparar ou avaliar requererá aprofundamento intelectual e certo nível de reflexão sobre a temática considerada. Dessa forma, a Taxonomia SOLO abrange as seguintes categorias de aprendizagem: Pré-Estrutural, Uni-Estrutural, Multi-Estrutural, Relacional e Abstrato. Os cinco níveis de compreensão podem ser brevemente descritos (Smith, 2013, p. 56):

Pré-estrutural: A tarefa não é adequadamente abordada; o aluno realmente não entendeu o assunto e escolheu um modo muito simplório para executá-la.

Uni-estrutural: A resposta do aluno se concentra apenas em um aspecto relevante.

Multi-estrutural: A resposta do aluno se concentra em vários aspectos relevantes, que são tratados de forma independente e aditiva. Neste nível a avaliação é principalmente quantitativa.

Relacional: Os diferentes aspectos foram integrados em um todo coerente. Neste nível normalmente atinge-se uma compreensão adequada de algum tópico.

Abstrato estendido: $O$ todo anterior integrado pode ser conceituado em um nível mais alto de abstração e generalizado para um novo tópico ou área.

Para envolver os estudantes em situações nas quais eles possam ser ativos, é necessário que o professor elabore Atividades de Ensino e Aprendizagem (Teaching Learning Activities, TLA) orientadas para este fim. As atividades devem possibilitar que os estudantes construam os conhecimentos e desenvolvam as habilidades necessárias para alcançar os objetivos pretendidos da aprendizagem (Mendonça, 2014, 2015).

Não podemos medir o aprendizado diretamente. Em vez disso, devemos fazer inferências a partir 
de evidências. Inferências consistentes dependem de avaliações alinhadas com o conteúdo (Smith, 2013, p. 21, grifos do original).

O Alinhamento Cognitivo é uma forma de se atingir a Aprendizagem Significativa proposta por Ausubel et al. (1978). A concepção básica é a de que o aprendizado individual se realiza mediante a necessária conexão e estabelecimento de nexos com estruturas significativas de conhecimento que a pessoa tenha construído anteriormente (Souza, 2016). A teoria da Aprendizagem Significativa (Ausubel, 2003) assinala ser necessário que o professor vença algumas barreiras para desenvolver a formação de alunos de nível superior, tais como: o professor tem que deixar de ser o principal responsável pela aprendizagem e deve conscientizar-se do seu papel de facilitador do processo, para provocar a aprendizagem, sem fornecer tudo pronto ao aluno.

Quando se programa a matéria a ser lecionada de acordo com o princípio de diferenciação progressiva, apresentam-se, em primeiro lugar, as ideias mais gerais e inclusivas da disciplina e, depois, estas são progressivamente diferenciadas em termos de pormenor e de especificidade (Ausubel, 2003).

Zabala \& Arnau (2010) afirmam que a aprendizagem será mais ou menos significativa quando ir muito além de implicar memorização ou compreensão superficial das ideias ou seja, a mera lembrança daquilo que se compreendeu, mas deve ser possível aplicar o conhecimento adquirido em contextos diferenciados.

\section{Mapas Conceituais e Aprendizagem Significativa}

O mapeamento conceitual é uma técnica muito flexível e em razão disso pode ser usado em diversas situações, para diferentes finalidades: instrumento de análise do currículo, técnica didática, recurso de aprendizagem, meio de avaliação (Moreira \& Buchweitz, 1993). Em 1963, a obra de Ausubel The Psychology of Meaningful Verbal Learning constituiu a primeira tentativa de apresentar uma teoria de aprendizagem baseada na proposta de que a aquisição e a retenção de conhecimentos resultam de um processo ativo, integrador e interativo entre o material usado no aprendizado e as ideias relevantes estruturadas na mente do aluno (Ausubel, 2003).

Baseando-se na Teoria da Aprendizagem Significativa (AS) de David Ausubel, Novak (1996) definiu o Mapa Conceitual como uma representação gráfica, em duas dimensões, de determinado conjunto de conceitos, sendo construído de forma a evidenciar as relações entre eles.

\section{Aprendizagem Baseada em Problemas (PBL)}

A Aprendizagem Baseada em Problemas/Projetos (Problem Based Learning, PBL) é uma metodologia de ensino-aprendizagem, colaborativa, construtivista e contextualizada na qual diferentes situações-problema são utilizadas para iniciar, direcionar e motivar a aprendizagem de conceitos, teorias e o desenvolvimento de habilidades e atitudes no contexto da sala de aula (Ribeiro, 2008). Inicialmente a abordagem PBL foi elaborada para ensino de Medicina, mas, como seus princípios são robustos, pode ser aplicada a outras áreas do conhecimento, sem perder sua configuração central, principalmente nas Engenharias.

A opção pela aprendizagem baseada em problemas propicia desenvolvimento de atividades educativas que envolvam participação individual, discussões coletivas críticas e reflexivas. A proposta didática compreende o ensino com uma visão complexa que proporciona aos alunos a convivência com uma diversidade de opiniões convertendo as atividades metodológicas em situações significativas para produção do conhecimento. Propicia ainda o acesso a maneiras diferenciadas de aprender e, especialmente, de aprender a aprender (Behrens, 2013).

\section{Ambientes Virtuais de Aprendizagem (AVA)}

Atualmente, proliferam os Ambientes Virtuais de Aprendizagem (AVA) disponíveis no "mercado educacional", que podem ser desenvolvidos tanto por empresas privadas, quanto por instituições educacionais. São classificados como softwares proprietários e softwares livres (Schlemmer, 2006). No desenvolvimento deste projeto foram considerados dois ambientes virtuais disponibilizados pela Universidade Federal do Amazonas: O Moodle e o Google Classroom. No Manual do Usuário do Moodle (2017) disponibilizado pelo GGTE (Grupo de Gestão de Tecnologias Educacionais) da Unicamp temos que:

"O ambiente virtual de aprendizagem Moodle contribui para ampliar as possibilidades de ensino e de aprendizagem. Ele é um software livre (open source), usado mundialmente em instituições de 
ensino. Possui diversas ferramentas que ajudam o desenvolvimento de materiais na web e que podem ser usados em cursos oferecidos tanto na modalidade presencial como na modalidade a distância. (GGTE/Unicamp, 2017)

Moodle é um Learning Management System (LMS) que gerencia cursos por meio de dados de frequência e acessos, disponibiliza recursos para publicação de materiais e atividades, além de oferecer meios de comunicação síncrona e assíncrona entre os participantes. Mantém uma comunidade internacional (site www.moodle.org) e abre a participação em fóruns de discussão e acesso a funcionalidades que ainda estão em fase de desenvolvimento, além de trazer outras informações que auxiliam a aprofundar o conhecimento sobre a plataforma. $\mathrm{Na}$ Universidade Federal do Amazonas esse AVA está vinculado ao Centro de Educação a Distância (CED) responsável por alocar as disciplinas que serão ofertadas a distância ou em modo semi-presencial.

O Google Classroom é plataforma educacional do Google para professores que auxilia na organização para melhoria da qualidade das aulas dadas a seus alunos. Este ambiente interativo junta algumas ideias simples para facilitar a comunicação entre professores e seus alunos. Com ele, os professores podem criar e receber tarefas, se organizar com a criação de pastas no Google Drive para cada uma das tarefas, e conversar em tempo real com seus estudantes. A UFAM possui cadastro junto ao Google Classroom, que facilita a abertura da turma (disciplinas) no ambiente.

\section{Métodos: desenvolvimento das estratégias didáticas de ensino}

O professor tem hoje, ao seu dispor, amplo leque de alternativas favoráveis à inovação didática que ajudam a promover junto aos estudantes, em sala de aula, a interação entre o conhecimento tácito e o conhecimento explícito (Barbosa \& Carneiro, 2020). Para melhorar o desempenho discente, é preciso empregar estratégias didáticas que possibilitem o envolvimento mais efetivo nas disciplinas como, por exemplo, o uso de softwares livres e/ou comerciais, mapas conceituais, entre outros. Dois exemplos empregados no presente estudo são a montagem de equipamento didático e o uso de ambientes virtuais de ensino-aprendizagem.

O desenvolvimento das estratégias didáticas baseou-se no modelo de pesquisa-ação e na concepção de Alinhamento Construtivo (Biggs, 1999). A sequência de etapas foi ajustada à disciplina ministrada, compreendendo a realização de atividades teóricas e práticas a fim de melhorar o entendimento do conteúdo pelos alunos e buscar atingir uma aprendizagem significativa dos conteúdos ministrados.

As propostas foram aplicadas em duas disciplinas da grade curricular do Curso de Engenharia de Petróleo e Gás, versão 2010: FTP008/Modelagem Geológica de Reservatórios e FTP002/Geofísica do Petróleo. Uma vez que as Atividades de Ensino foram planejadas de acordo com a necessidade de cada disciplina, para a elaboração do Plano das aulas considerou-se o conteúdo programático a ser ministrado pelo docente. Inicialmente a primeira turma do primeiro semestre do ano de 2018 desenvolveu as atividades na disciplina de Modelagem Geológica de Reservatórios. É importante ressaltar que a faixa etária dos estudantes matriculados nas duas turmas é de 19 a 23 anos, fator capaz de limitar a comparação dos resultados obtidos com dados disponíveis na literatura.

O primeiro passo foi a inserção das disciplinas no Ambiente Virtual de Aprendizagem que foi Moodle ou Google Classroom; em um caso específico, uma turma foi inserida nos dois ambientes a fim de se comparar o uso de ambos. As aulas foram elaboradas em função das estratégias didáticas, empregando Alinhamento Construtivo, Aprendizagem Baseada em Problemas, Aprendizagem Significativa e Mapas Conceituais. Em cada semestre uma turma específica foi considerada: em 2018/1 as atividades envolveram a turma de FTP008/Modelagem Geológica e em 2018/2 as atividades foram realizadas na turma de FTP002/Geofísica do Petróleo. No ano de 2019 o processo foi repetido nas mesmas disciplinas para comparar resultados das turmas que participaram da aplicação das propostas nos dois anos (2018 e 2019).

O processo de avaliação das atividades guardou correspondência direta com os objetivos pretendidos de aprendizagem estabelecidos pela professora. Assim, ao final das atividades de cada disciplina, o aluno deveria deter ou dominar os seguintes conceitos ou habilidades:

FTP002-Geofisica do Petróleo: ao final da disciplina o aluno deve ser capaz de conceituar a Geofísica; classificar a Geofísica no cenário das Ciências da Terra; classificar os métodos geofísicos utilizados para a prospecção de hidrocarbonetos; identificar o princípio de funcionamento de cada método geofí- 
sico; conceituar as propriedades físicas investigadas pelos métodos geofísicos; manipular softwares geofísicos disponibilizados pela professora; descrever a importância dos métodos geofísicos para a prospecção de hidrocarbonetos na indústria do petróleo.

FTP008-Modelagem Geológica de Reservatórios: ao final da disciplina o aluno deve ser capaz de utilizar os softwares disponibilizados e conceituar, dentre outros termos: rochas-reservatório; rocha selante; trapas.

Em ambas as disciplinas a professora também esperava que o aluno conseguisse elaborar um mapa conceitual a partir dos conteúdos ministrados. No geral os alunos ao final deveriam utilizar os softwares disponibilizados em ambas as disciplinas. Os critérios foram estabelecidos com base no conceito de rubricas, conjugando assim a análise de aspectos qualitativos e quantitativos. As ferramentas de coleta de dados envolveram a pesquisa participativa com o uso de questionário elaborado no Google Forms, não sendo obrigatória a participação e a avaliação das atividades aplicadas pela professora a partir das notas dos alunos naquele semestre. O conteúdo do questionário compreendeu perguntas abertas sobre os ambientes virtuais de aprendizagem nas turmas trabalhadas. As perguntas foram discursivas ou objetivas, existindo a possibilidade de responder "Sim" ou "Não", dar notas de 0 a 5 sendo 0 a mínima e 5 a máxima, ou responder com sua opinião pessoal. Após a análise quantitativa foi considerada também a análise qualitativa das respostas para avaliar se houve aprendizagem significativa dos conteúdos ministrados.

\section{Resultados obtidos}

A pesquisa envolveu tanto a investigação quantitativa (mensuração da quantidade de respostas dos alunos por meio da construção de gráficos e análi- se dos dados) quanto a qualitativa (contato direto e interativo do pesquisador com a aplicação das estratégias didáticas), a partir das aulas ministradas ao longo de quatro semestres (2018 e 2019). Sendo assim, os resultados obtidos são descritos com foco no processo de ensino e aprendizagem.

O primeiro semestre de 2018 contemplou a disciplina FTP008/Modelagem Geológica de Reservatórios. A disciplina foi inserida no Google Sala de Aula com a finalidade de haver maior integração entre docente e alunos. A Figura 1 ilustra a interface do Ambiente Virtual de Aprendizagem. Além disso, também foram inseridos no mesmo ambiente o monitor da turma para facilitar o processo de comunicação, o cronograma e o plano das atividades das aulas.

A elaboração do Plano de Atividades de cada disciplina aplicou a proposta de Biggs (1999) do Alinhamento Construtivo, que conecta o planejamento do ensino, as ações de ensino e o processo de avaliação. Para priorizar os resultados de aprendizagem atingidos pelos estudantes, foi importante definir o objetivo da disciplina e os conteúdos ou habilidades que o aluno precisa aprender ou desenvolver para complementar seu conhecimento em Engenharia de Petróleo. Uma vez definida a estratégia de Alinhamento Construtivo, no início das aulas a professora verificou quais conhecimentos prévios os alunos apresentavam a respeito dos conteúdos que seriam ministrados na disciplina FTP008/Modelagem Geológica. Nesta etapa foram aplicados Mapas Conceituais para as definições mais simples de Geologia Geral: por exemplo, definição de rocha sedimentar e sua classificação. A Figura 2 é um mapa conceitual elaborado por um grupo de alunos da disciplina FTP008/Modelagem Geológica de Reservatórios.

$\equiv$ FTPOO8-MODELAGEM GEOLÓGICA DE R

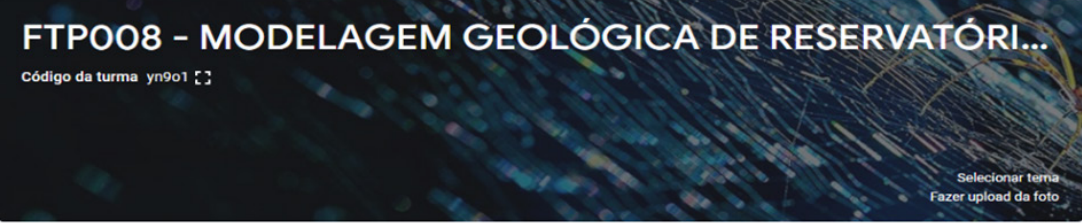

(2)

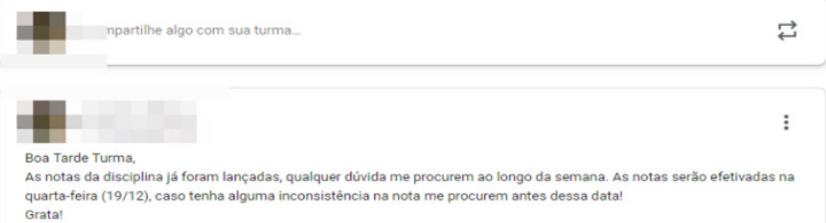

हु్

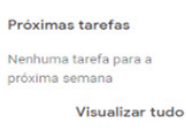

quarta

Figura 1. Interface de avisos do Google Classroom 
A partir dos mapas conceituais elaborados pela turma, baseados na Teoria da Aprendizagem Significativa (AS) de David Ausubel (Ausubel et al., 1978), observa-se que cada mapa conceitual se tornou uma representação gráfica na qual se conectam diversos conceitos.

Para desenvolver a proposta de Aprendizagem Baseada em Problemas (PBL), a professora solicitou como tarefa de conclusão da disciplina a elaboração de um projeto de modelagem geológica de um conjunto de poços de petróleo em uma determinada localidade. A partir dos dados disponibilizados os alunos teriam que apresentar um modelo geológico para a área de estudo proposta pela professora utilizando o software de SGeMS (Stanford Geostatistics Modelling Software), que é um pacote de computador de código aberto para resolver problemas envolvendo variáveis espacialmente relacionadas. Assim, os alunos foram divididos em dois grandes grupos para a realização do projeto. $\mathrm{O}$ trabalho foi realizado como avaliação final, envolvendo assim todo o conteúdo ministrado ao longo do semestre.

O mesmo processo foi realizado na disciplina FTP002/Geofísica do Petróleo no segundo semestre de 2018, com o diferencial de que a disciplina foi incluída no AVA Moodle; no ambiente, além dos exercícios práticos, foi realizada também uma avaliação parcial. Nesta disciplina não houve aplicação na linha de Aprendizagem Baseada em Problemas (PBL) mas sim a utilização de ferramenta de um software disponibilizado no próprio laboratório da Faculdade de Tecnologia, MATLAB ${ }^{\circledR}$ (MATrix LABoratory), que é um sistema interativo que permite a resolução de problemas numéricos. A ferramenta SeisLab foi instalada no software para visualização dos traços sísmicos vistos no conteúdo de Métodos Sísmicos da disciplina de FTP002/ Geofísica do Petróleo (Conceição \& Simas, 2019). Com apoio de outro software Livre (GêBR), foi possível que os alunos comparassem o uso de ambos os softwares.

No ano de 2019, a ferramenta MRST (Reservoir Simulation Toolbox) foi incluída na disciplina de FTP008/Modelagem Geológica, que realiza modelagem e simulação de reservatórios de petróleo a partir do software MATLAB. No capítulo sobre Geologia Estrutural, utilizou-se como prática a projeção estereográfica com o uso manual do Diagrama de Schmidt e o uso do software ESTER 2.0 (Simas \& Miguel, 2019). Sendo assim, neste semestre de 2019, para esta disciplina foram utilizados três softwares, o ESTER 2.0, o SGeMS e o MRST para MATLAB, no entanto somente os dois últimos foram utilizados para a elaboração do projeto final a fim de aplicar o PBL.

Na disciplina FTP002/Geofísica do Petróleo também foi montado um equipamento didático

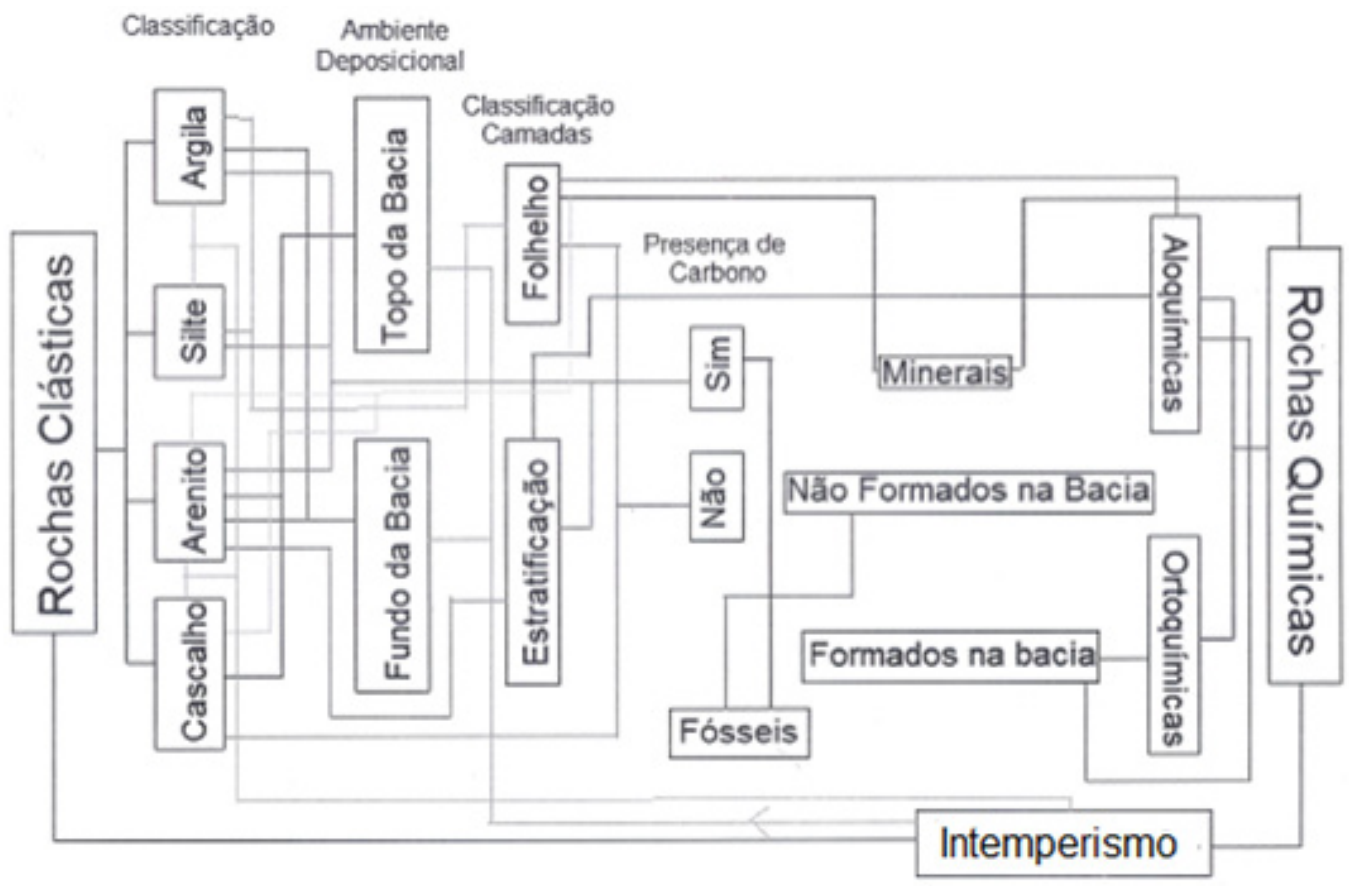

Figura 2. Mapa Conceitual sobre rocha sedimentar e sua classificação

\begin{tabular}{c|c|c|c|c|c}
\hline C Terrae Didat. & Campinas, SP & v.17 & $1-11$ & $\mathrm{e} 021015$ & 2021 \\
\hline
\end{tabular}


para realização de prática envolvendo eletrorresistividade, dentro do tema de Métodos Geoelétricos. A atividade tornou possível relacionar a Aprendizagem Significativa com Aprendizagem Baseada em Problemas. O uso do equipamento também possibilitou o uso de um novo software para a realização do modelamento dos dados adquiridos a partir da prática com o equipamento didático, o software utilizado foi o Surfer 9.

\section{Montagem de instrumentos}

A disciplina Geofísica do Petróleo é ofertada somente para o curso de Engenharia de Petróleo e Gás da UFAM e não dispõem de laboratórios nem equipamentos para atividades práticas ao longo do semestre. A fim de aprimorar o ensino na disciplina, a partir do Alinhamento Construtivo (Biggs, 2011) e para tornar mais significativo o processo de ensino-aprendizagem, utilizou-se a montagem de um equipamento que fosse de fácil entendimento e aplicação pelos alunos (Fig. 3). A utilização de um módulo didático de eletrorresistividade aumentou o interesse dos alunos no Capítulo estudado (Métodos Geoelétricos), reduzindo a quantidade de alunos que deixavam de frequentar a disciplina e aumentando o índice de presença nas aulas em quase $100 \%$. Levando em conta o engajamento da turma, os alunos apresentaram maior atividade graças à metodologia de ensino aplicada.

\section{Avaliação das estratégias didáticas}

Ao final de cada disciplina o aluno matriculado podia responder a um questionário de avaliação das propostas, no qual tínhamos as principais perguntas relacionadas ao uso dos softwares: "O aluno já havia utilizado algum software para aprendizagem?" Os resultados estão representados na Figura 4, envolvendo as seguintes questões: "Houve facilidade no manuseio do software?" (Fig. 4a). "Foi possível correlacionar a teoria com a prática?" (Fig. 4b).

$\mathrm{Na}$ Figura 4a, observa-se que, dos alunos que responderam ao questionário em ambas as disciplinas, 64\% ainda não haviam utilizado qualquer software para aprendizado de alguma disciplina. $\mathrm{Na}$ Figura $4 b$, observa-se que os alunos que responderam ao questionário em ambas as disciplinas acharam fácil o manuseio dos softwares (55\%), enquanto $41 \%$ dos estudantes acharam inter- mediário o nível de dificuldade para manusear os softwares (nem fácil e nem difícil).

$\mathrm{Na}$ Figura 5, observa-se que os alunos que responderam ao questionário em ambas as disciplinas conseguiram correlacionar o assunto teórico com a parte prática a partir do uso dos softwares (aproximadamente 23\%). Foram ainda realizadas perguntas a respeito de uso do equipamento didá-

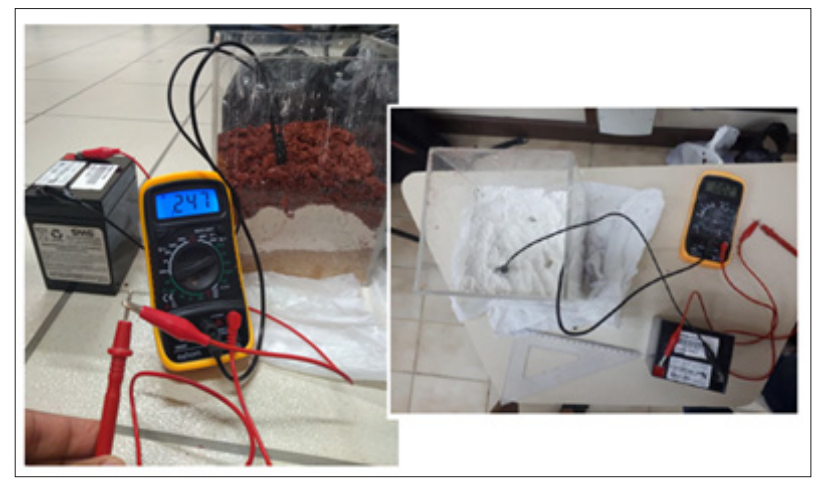

Figura 3. Equipamento didático. Fonte: os autores
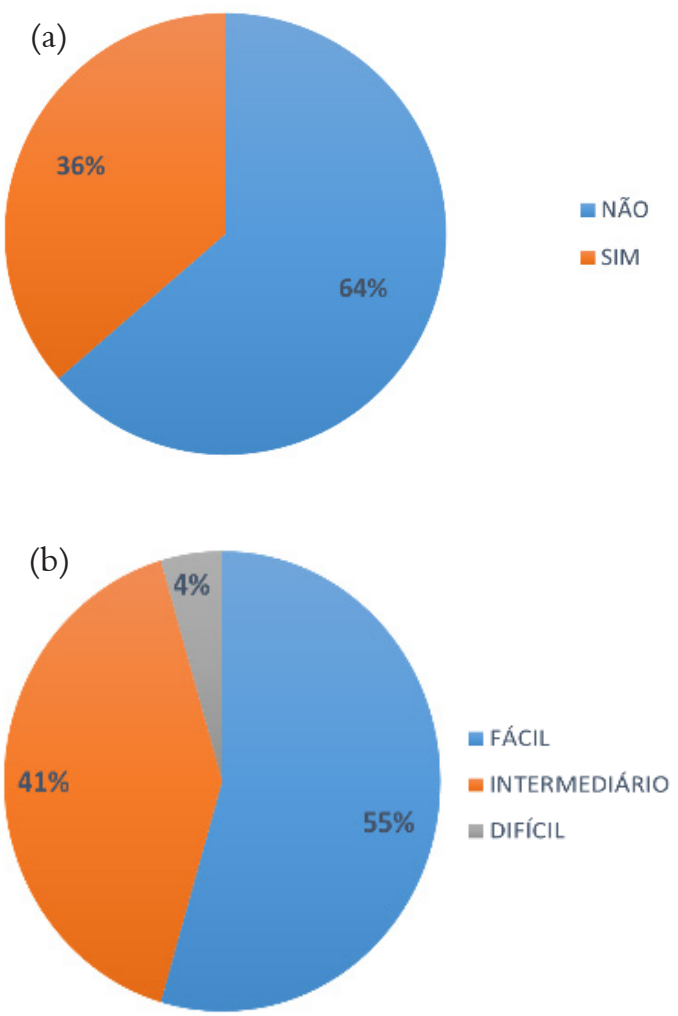

Figura 4. Respostas obtidas sobre: (a) Houve utilização anterior de algum software para aprendizagem? (b) Como classifica o manuseio de softwares? Fonte: os autores

\begin{tabular}{c|c|c|c|c|c}
\hline (C) Terrae Didat. & Campinas, SP & v.17 & $1-11$ & $\mathrm{e} 021015$ & 2021 \\
\hline
\end{tabular}




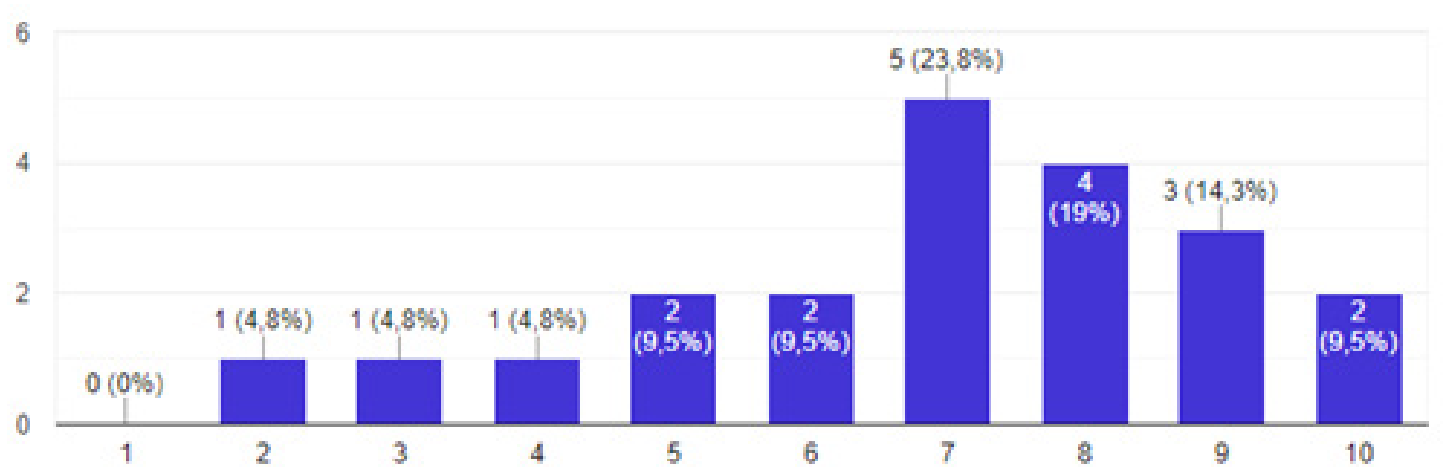

Figura 5. Correlação da teoria com a prática a partir do uso dos softwares. Fonte: os autores

tico. As principais perguntas foram: "O manuseio do equipamento foi fácil?” (Fig. 6). (Fig. 6a). "Foi possível realizar o entendimento do conteúdo teórico com a prática?" (Fig. 6b).

$\mathrm{Na}$ Figura 6a, observa-se que os alunos que responderam ao questionário na disciplina de FTP002/ Geofísica do Petróleo sobre uso do equipamento didático, acharam o manuseio de certa forma fácil (59\%), enquanto $36 \%$ acharam o manuseio fácil e apenas $5 \%$ acharam o manuseio do equipamento difícil. Na Figura 6b, observa-se que os alunos que responderam ao questionário da disciplina de FTP002/Geofísica do Petróleo sobre uso do equipamento didático conseguiram relacionar a parte teórica (vista em sala de aula) com a prática (vista no laboratório com o uso do equipamento). Os alunos que correlacionaram a teoria e a prática correspondem a $95 \%$ da turma.

$\mathrm{Na}$ análise qualitativa empregou-se a técnica da pesquisa-ação, que valoriza as ações, percebidas pelo professor, que são suscetíveis de mudança e que exigem resposta prática. A situação problemática é interpretada a partir do ponto de vista das pessoas envolvidas, baseando-se, portanto, nas

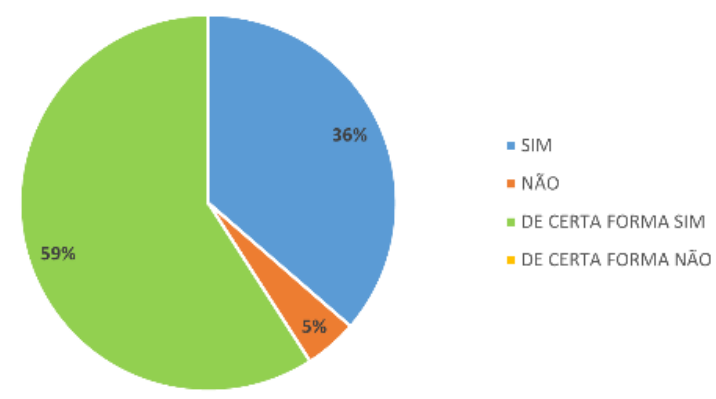

(a)

representações do professor e dos alunos sobre a situação. $\mathrm{Na}$ análise qualitativa observou-se um maior engajamento dos alunos na realização das atividades em ambas as disciplinas (Geofísica do Petróleo e Modelagem Geológica de Reservatórios). Como a pesquisa-ação é auto avaliativa, as modificações introduzidas na prática são constantemente avaliadas no decorrer do processo de intervenção e ofeedback obtido do monitoramento da prática se traduz em modificações, mudanças de direção e redefinições, conforme necessário, trazendo benefícios para a prática.

\section{Discussão}

A ascensão da indústria petrolífera brasileira esteve diretamente ligada à difusão do ensino superior voltado à área. Além do incentivo criado pela exploração offshore na década de 1990, um novo pulso de criação de cursos de bacharelado surgiu a partir de 2006, ano em que surgiram os primeiros indícios dos vastos depósitos de hidrocarbonetos do Pré-Sal. Neste novo contexto, diversas instituições de ensino superior fundaram cursos de Bacharelado

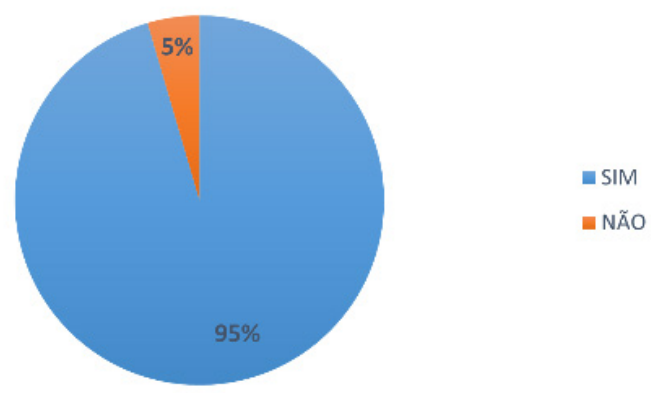

(b)

Figura 6. Utilização do equipamento didático (a). Entendimento da teoria a partir da prática com equipamento (b). Fonte: os autores 
em Engenharia de Petróleo, chegando a mais de 35 oferecimentos em território brasileiro no ano de 2012 (Nobre et al., 2020).

O curso de Engenharia de Petróleo e Gás no Amazonas foi criado em 2009 e iniciou suas atividades em 2010 sendo a UFAM incluída no conjunto de instituições de ensino superior que fundaram um curso em Engenharia de Petróleo.

Ao iniciar as atividades na Universidade Pública a professora já se encontrava com três anos de experiência na área da docência e ainda sentia muita dificuldade em transmitir os conhecimentos das disciplinas devido à formação técnica. Era preciso que a transmissão do conhecimento acontecesse com clareza e precisão mas, devido à falta de laboratórios específicos para as aulas práticas, os alunos tinham cada vez mais dificuldade em entendê-las; consequentemente, o índice de reprovação foi muito grande sendo um dos fatores que prejudicavam o andamento das demais disciplinas de Geociências da grade curricular do curso.

A partir das observações realizadas na oferta das disciplinas sem aplicações metodológicas efetivas, iniciou-se uma reflexão sobre o processo de ensino e de aprendizagem. A pesquisa bibliográfica revelou que o planejamento das aulas é essencial para as atividades do docente; consequentemente, a definição dos objetivos e o processo de avaliação são os principais elementos da etapa de planejamento o que conduziu a pesquisa para a Teoria de Alinhamento Construtivo de Biggs. Pelo fato de o Engenheiro de Petróleo e Gás da UFAM ter como uma de suas principais bases de formação as disciplinas de Geociências, a utilização das estratégias didáticas expostas mitigou, de certa forma, a falta de laboratórios, e propiciou o uso da linguagem visual e do raciocínio espacial, cuja importância na Geologia é indiscutível. Assim, a aplicação do Alinhamento Construtivo nas disciplinas de Geofísica e Modelagem Geológica desde o planejamento das aulas propiciou maior interação entre alunos e professora, favorecendo a compreensão dos conteúdos.

As dificuldades no processo de ensino e aprendizagem no curso de Engenharia sem acesso a laboratórios específicos revelaram a necessidade de inovação das estratégias didáticas, de modo a preparar os discentes de graduação para uma efetiva construção de saberes. As estratégias didáticas utilizadas nas disciplinas de Modelagem Geológica de Reservatórios e Geofísica do Petróleo permitiram atingir resultados importantes, uma vez que:

- Os estudantes acentuaram que o uso de mapas conceituais foi extremamente importante para o aprendizado conceitual: os mapas conceituais elaborados pelos alunos facilitaram o entendimento dos conceitos aplicados tanto na disciplina de Modelagem Geológica de Reservatórios quanto na disciplina de Geofísica Aplicada.

- A estratégia da produção e apresentação dos materiais didáticos dinamizou as aulas que, de forma geral, apresentam um corpo teórico às vezes bastante complexo. Ao propor tal estratégia objetivava-se a revisão dos conceitos por parte dos discentes, visto que já estudaram tais conteúdos em anos anteriores.

- A utilização de softwares nas disciplinas de Geofísica do Petróleo e Modelagem Geológica de Reservatórios trouxe a possibilidade de uso da linguagem visual e o raciocínio espacial, suprindo a carência de laboratórios.

Houve dificuldade de se comparar os resultados obtidos com outros dados existentes na literatura, devido à mencionada faixa etária dos estudantes matriculados, entre 19 e 23 anos. A avaliação positiva da aplicação das estratégias de ensino pelos estudantes observada na análise quantitativa e acompanhada pelo professor na técnica de pesquisa-ação para a análise qualitativa fomenta correlações com assuntos cotidianos, engaja os estudantes nas disciplinas e fortalece a relação professor-aluno. Ao se sentir inserido de modo dinâmico, o aluno assumiu o papel de "construtor" das disciplinas, havendo maior participação nas atividades propostas.

\section{Conclusões}

A elaboração do Plano de Atividades no início das disciplinas de Geofísica do Petróleo e Modelagem Geológica de Reservatórios permitiu à docente e pesquisadora detectar as dificuldades apresentadas pelos alunos e serviu de base para a formulação das estratégias didáticas durante o desenvolvimento da pesquisa.

A aplicação das estratégias didáticas (mapas conceituais e aprendizagem baseada em projetos) foi avaliada de forma altamente positiva pelos alunos. O uso da aprendizagem baseada em projetos (PBL) no ambiente acadêmico, sobretudo no vasto campo das Geociências, exige por parte do estudante maior pesquisa e análise crítica da literatura mas, ao mesmo tempo, potencializa a formação dos alunos para o mercado de trabalho. Os alunos 
concordaram que o PBL os incentivou a trazer ideias, habilidades e sugestões para o projeto proposto pela professora na disciplina de Modelagem Geológica de Reservatórios. Ao longo do desenvolvimento da proposta houve melhoria da expressão oral e aprofundamento de conceitos trabalhados nas discussões e apresentações em grupo. Os alunos conseguiram elaborar um mapa conceitual a partir dos conteúdos ministrados; a maioria teve dificuldade com o uso de software livre pois este demanda maior conhecimento em programação de computadores; ao mesmo tempo, relataram ser mais fácil usar softwares comerciais.

Observou-se que o estabelecimento prévio dos resultados pretendidos da aprendizagem permitiu avaliar se o alinhamento cognitivo foi alcançado ou não. Na Taxonomia SOLO pode-se afirmar que as turmas alcançaram os níveis Multi-Estrutural e Relacional. No Nível Multi-Estrutural (elaboração de mapas conceituais e uso do equipamento didático) os discentes conseguiram lidar com múltiplas informações relevantes e corretas, mas as informações não foram devidamente relacionadas ou contextualizadas. Disso resulta que o aluno apresenta dificuldades em compor o todo. No Nível Relacional (uso dos softwares e PBL) os discentes foram capazes de perceber as relações entre as várias informações e como elas se integram para formar o todo.

\section{Agradecimentos}

Agradecemos os discentes do curso de Engenharia de Petróleo e Gás e em especial modo os que participaram do desenvolvimento dessa pesquisa por meio de Projetos de Iniciação Científica (PIBIC) e de Projetos de Inovação Tecnológica (PIBITI). Os autores agradecem ao CNPq (Conselho Nacional de Desenvolvimento Científico e Tecnológico) pela concessão de bolsa de produtividade em pesquisa, nível 2, aos autores G. Basilici e C. D. R. Carneiro.

\section{Referências}

Alvarenga, C. E. A. (2011). Autoeficácia de professores para utilizarem tecnologias de informática no ensino. Tese (Doutorado). Campinas, SP, Brasil, Faculdade de Educação, Universidade Estadual de Campinas. URL: http://repositorio.unicamp.br/jspui/handle/ REPOSIP/251367. Acesso 15.03.2021.

Ausubel, D. P., Novak, J. D. \& Hanesian, H. (1978). Educational psychology. New York: Holt, Rinehart and Winston.

Ausubel, D. P., Novak, J. D. \& Hanesian, H. (1980).
Psicologia educacional. Trad. Eva Nick e outros. Rio de Janeiro, Ed. Interamericana. 626p.

Ausubel, D. P. (2003). Aquisição e retenção de conhecimentos: uma perspectiva cognitiva. Lisboa: Plátano Ed. Técnicas. Trad. The acquisition and retention of knowledge: a cognitive view. (2000). Klüwer Acad. Publ. Co.

Barbosa, R., \& Carneiro, C. D. R. (2020). Régua de Inovação: uma ferramenta de apoio à Educação em Geociências. Terre Didatica, 16, 1-12, e020015. doi: 10.20396/td.v16i0.8658118.

Behrens, M. A. (2013). Metodologia de Aprendizagem Baseada em Problemas. In: Veiga, I. P. A. (2013). Técnicas de Ensino: Novos Tempos, Novas Configurações. Campinas: Ed. Papirus. p. 163-187.

Biggs, J. \& Tang, C. (1999) Teaching for Quality Learning at University. $3^{\text {rd }}$ ed. The Society for Research into Higher Education.

Conceição, T. A., \& Simas, J. L. (2019). Aplicação do alinhamento construtivo a partir da validação da ferramenta Seislab para MATLAB® para uma aprendizagem significativa. Terre Didatica, 15(2), 1-3, e019044. doi: 10.20396/td.v15i0.8657530.

Grupo de Gestão de Tecnologias Educacionais da Unicamp (GGTE/Unicamp). (2017). Acesso aos sistemas. Campinas, Universidade Estadual de Campinas. URL: https://ggte.unicamp.br/wp/. Acesso 16.03.2021.

Mello, C. H. P.; Turrioni, J. B.; Xavier, A. F.; Campos, D. F. (2012). Pesquisa-ação na engenharia: Proposta de estruturação para sua condução. Produção, 22(1), 1-13.

Mendonça, A. (2014). Teoria do Alinhamento Construtivo: fundamentos e aplicações. URL: http://www. academia.edu/17729627/Teoria_do_Alinhamento_Construtivo_-_Fundamentos_e_Aplica\% $\%$ C $\%$ A7\%C3\%B5es_Andr\%C3\%A9 9 a_Mendon\%C3\%A7a. Acesso 02.06.2020.

Mendonça, A. P. (2015). Alinhamento Construtivo. Fundamentos e Aplicações. In: Gonzaga, A. M. (Org.) (2015). Formação de Professores no Ensino Tecnológico: Fundamentos e Desafios. Curitiba: CRV. p. 109-130.

Moreira, M. A. \& Buchweitz, B. (1993). Novas estratégias de ensino e aprendizagem: os mapas conceituais e o Vê epistemológico. Lisboa: Plátano Edições Técnicas.

Neves, J. L. (1996). Pesquisa Qualitativa. Características, Usos e Possibilidades. São Paulo, Caderno de Pesquisas em Administração, 1(3).

Nobre, A. G., Andrade, P. A., \& Florêncio, O. (2020). Disciplinas de Geociências do Bacharelado em Engenharia de Petróleo da Universidade de São Paulo comparadas com a proposta curricular da Society of Petroleum Engineers. Terre Didatica, 16, 1-11, e020020. doi: 10.20396/td.v16i0.8657989.

Novak, J.D. \& Gowin, D.B. (1996). Aprender a aprender. Lisboa: Plátano Edições Técnicas. Trad. de Learning how to learn. (1984). Ithaca, N.Y.: Cor- 
nell Univ. Press.

Plataforma Google Classroom. (s.d.). Google Sala de Aula. URL: https://classroom.google.com. Acesso: 21/03/2021.

Plataforma Moodle. (s.d.) Moodle sandbox demo. URL: https://sandbox.moodledemo.net/. Acesso 21.03.2021

Ribeiro, L. R. C. (2008). Aprendizado baseado em problemas. São Carlos: UFSCAR. (Fund. Apoio Institucional).

Schlemmer, E. (2006). Avaliação de Ambientes Virtuais de Aprendizagem na perspectiva da complexidade. In. XVII Simpósio Brasileiro de Informática na Educação, (SBIE). Brasília, Universidade de Bra- sília (UNB)/Universidade Católica de Brasília (UCB).

Simas, J. L., \& Miguel, G. F. (2019). Uso de software de projeção estereográfica como recurso para a aprendizagem significativa em um Curso de Engenharia de Petróleo e Gás. Terrce Didatica, 15(2), 1-7, e019045. doi: 10.20396/td.v15i0.8657549.

Souza, P.R. (2016). Aprendizagem significativa e alinhamento construtivo: uma proposta para o ensino de circuitos elétricos. Dissertação de Mestrado. Manaus/AM, Instituto Federal do Amazonas (IFAM).

Zabala, A, \& Arnau, L. (2010). Como aprender e ensinar competências. Porto Alegre: Artmed. 